\title{
How Social Behaviour Links Environment and Body Size in Mammalian Carnivores
}

\author{
Steven H. Ferguson ${ }^{*}, 1$ and Serge Larivière ${ }^{2}$ \\ ${ }^{I}$ Fisheries and Oceans Canada, 501 University Crescent, Winnipeg, MB, R3T 2N6, Canada \\ ${ }^{2}$ Cree Hunters and Trappers Income Security Board, 2700 Boulevard Laurier, Sainte-Foy, QU, G1V 4K5, Canada
}

\begin{abstract}
Many hypotheses for larger body size with increasing latitude invoke environmental explanations, such as decreasing temperature. We propose a novel explanation that links environmental selection pressures and body size with spacing behaviour. We test for causal pathways between (1) environment (snow, latitude, primary productivity, seasonality, and temperature) and (2) spacing behaviour (home range size and population density) and (3) body size and sexual size dimorphism using structural equation modelling of independent contrasts derived from 101 mammalian terrestrial carnivore species. Although strong intercorrelations existed among all five environmental variables, primary productivity and seasonality best related to body size and size dimorphism. Using information-theoretic approach to select optimal model fit established that body size was not influenced directly by environment but rather through the intermediary variables, home range or density. For example, species living in highly seasonal environments were associated with larger home ranges and low density that in turn selected for larger body mass and greater sexual size dimorphism. Thus, spacing behaviour provides an important evolutionary link explaining interspecific body size variation.
\end{abstract}

\section{INTRODUCTION}

Two general rules in evolutionary ecology are that species evolved larger body size and greater sexual size dimorphism at higher latitudes. Various factors have been attributed as responsible for increasing body size with latitude, including latitudinal clines in primary productivity $[1,2]$; ability to survive environmental unpredictability characteristic of higher latitudes by enhancing thermoregulation and/or resisting starvation [3-5]; decreased competition or increased predation [6]; life-history adjustment to colder environments [7]; and Bergmann's rule [8], which has been interpreted as a prediction that surface area/mass for larger animals provides better adaptations against cold temperatures [9]. Body size influences and is influenced by behaviour, population dynamics and life history. Body size has been proposed to relate to latitudinal and seasonal variation [10] and clines of size $v s$ latitude are similar in northern and southern hemispheres [11]. Although previous authors mentioned that environmental stability might be a factor determining body size diversity, they have not suggested specific mechanisms by which this could happen $[12,13]$.

A possibly mechanism for terrestrial mammals is seasonal snow conditions that affect the movements of animals and subsequently lead to adaptations, such as delayed implantation, to overcome limitations posed by social behaviour [14]. Similarly, Bergmann's rule may be more related to seasonality than to temperature $[15,16]$. Thus among terrestrial animals, a novel explanation for the relationship of larger size with latitude is the hypothesis that (1) animals living at high latitudes exist at lower density and occupy larger home ranges because of seasonality and snow fall, and

*Address correspondence to this author at the Fisheries and Oceans Canada, 501 University Crescent, Winnipeg, MB, R3T 2N6, Canada;

E-mail: steve.ferguson@dfo-mpo.gc.ca consequently, (2) have evolved the adaptation of large body size to facilitate movement as a means of overcoming the difficulties of acquiring food and mates while living in seasonally cold environments. Thus, life-history traits, such as body size, may ultimately be derived from living in specific environments whereas the proximate selection pressure is social behaviour and mating systems [17-19].

For mating, the one sex (usually males) that is responsible for finding the other sex (usually females) needs to move about more during the mating season $[14,20]$. Therefore, a consequence of living at low densities and occupying large ranges is that greater sexual size dimorphism will also occur with increasing latitude. This leads to the additional expectation that species inhabiting high latitudes would display greater size dimorphism than low latitude species. Social behaviour does not always have to be the recipient of environmental selection pressure; behaviour is a life-history force of its own, and capable of modifying morphological traits $[21,22]$. Both large-scale patterns of body size variation may have similar underlying causes [23].

We used data on terrestrial mammalian carnivores to test for a relationship between environment (snow, temperature, productivity, and seasonality) and spacing behaviour (density and home range size) and body size or sexual dimorphism. We used phylogenetic independent contrasts because species do not represent independent data points [24, 25]. Path analysis using structural equation modeling [26] was the statistical analysis technique used to test causal hypotheses explaining the evolution of body size and sexual size dimorphism. We generate plausible hypotheses represented by graphical path models (Fig. 1) that estimate the relative contributions of species' traits to the evolution of body size patterns. We test among the multiple causal hypotheses explaining the evolution of body size using an informationtheoretic approach. Here, Akaike's information criterion (AIC) provides the quantitative method to choose a final 
model that has both simplicity and high predictive power [27].

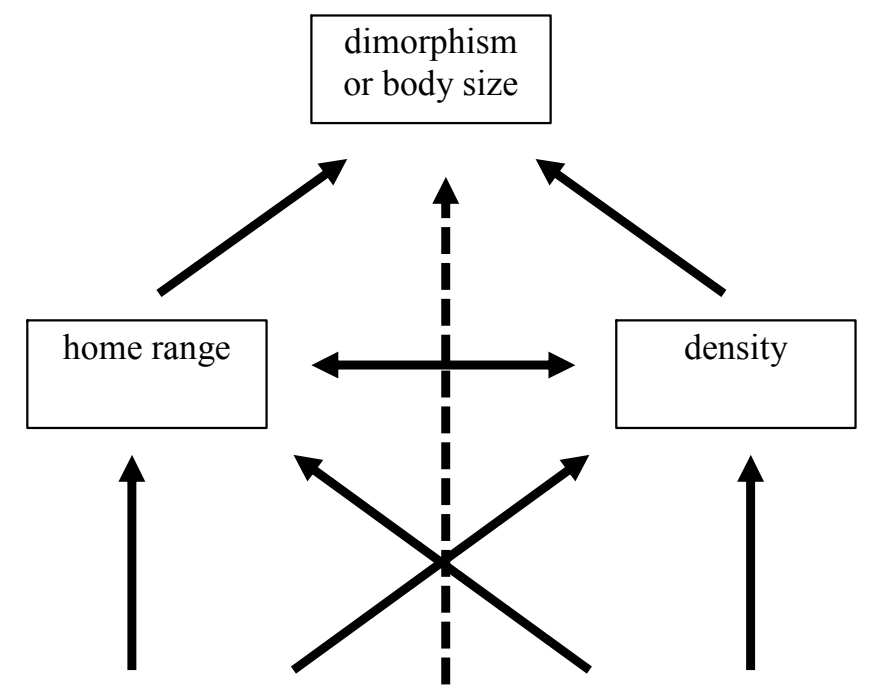

environmental variables

Fig. (1). Hypothesized path models predicting the influence of environment ( 5 variables) on behaviour (population density, home range size) and body size/sexual size dimorphism. Environmental characteristics are the assumed explanatory causal pattern and subsequent tests assessed model fit with (solid lines) or without (dashed line) the intermediate social behaviour variables.

\section{MATERIALS AND METHODS}

\section{Data Sources}

We obtained published data on species' traits from 8 families (of 12), 60 genera, and 101 species of terrestrial mammalian carnivores (e.g., Mammalian Species articles) [28]. We calculated an index of sexual size dimorphism as the ratio of male mass/female mass [29]. Data on density and home range of species were obtained from summary literature and means of population estimates were calculated for species. Summaries of population studies across a species' geographic range were used to represent species means although we recognize the assumptions inherent to this approach [30] and the bias in geographic distribution of species well enough studied to be included (e.g, $25 \%$ of species from southern hemisphere). We used the phylogenetic tree and branch lengths proposed by Bininda-Emonds [31] and the taxonomy of Wozencraft [32].

Longitude and latitude of the midpoint of each species historical distribution was obtained using maps from Mammalian Species accounts and world maps [28]. We used the absolute values for latitude to compare similar latitude locations in the northern (positive; $\mathrm{n}=90$ ) and southern (negative; $\mathrm{n}=30$ ) hemispheres. Environmental variables included seasonality, primary productivity, snow accumulation, and temperature, and were calculated using data from 13,332 weather stations distributed over the globe and then temporally averaged from 30-year normals and spatially interpolated to a regular grid of $1^{\circ}$ by $1^{\circ}$ latitude-longitude intervals [33]. Seasonality was calculated as the coefficient of varia- tion of monthly $(n=12)$ values of actual evapotranspiration $\left(\mathrm{mm} \cdot \mathrm{m}^{-2}\right)$ using a water budget analysis $[34,35]$. Actual evapotranspiration generally increases with solar input, precipitation, and soil water holding capacity and is highly correlated with primary productivity [12, 36, 37]. Lieth's [38] algorithm was used to convert actual evapotranspiration to total net primary productivity $\left(\mathrm{g} \cdot \mathrm{m}^{-2} \cdot \mathrm{y}^{-1}\right)$. Larger primary productivity values and larger coefficients of variation indicated greater energy and seasonality within a species' geographic range, respectively.

\section{Statistical Analyses}

For all traits, $\log _{10}$-transformed data distributions did not differ significantly from normality using Wilk-Shapiro normality test. Data points that vary with phylogenetic history violate the statistical assumption of independence and therefore require phylogenetic corrections [24]. Consequently, we used phylogenetically corrected analyses. Standardized independent contrasts were calculated by dividing the unstandardized contrast by the standard deviation [39] using the Phenotypic Diversity Analysis Program (PDAP version 5) PDTREE module $[25,40]$. General linear models of standardized independent contrasts were forced through the origin. Diagnostic tests were used to determine if branch lengths were standardized properly and that the assumption of Brownian evolution was appropriate [41].

Since the benefits of larger body size may be multiple $[42,43]$, we tested for relationships among the reduced variable set using the multiple hypothesis structure [44] of path analysis and structural equations [45]. An a priori path model approach was used to generate multiple models based on a proposed hypothesis and mechanistic understanding of relationships between variables (Fig. 1). The logic for the selected models was to select a subset of best fit models that included (1) environment as the initial causal variable [14] and (2) body size or sexual dimorphism as the final outcome [46]. The social behaviour hypothesis was tested by comparing model fit between those models having spacing behaviour traits (home range and density) included as intermediate variables between 1 and 2 and those models that linked 1 and 2 directly. Fit was assessed according to the informationtheoretic approach (Akaike's information criterion).

The adjusted trait values were used in model comparisons with the Covariance Analysis of Structural Equations (SAS 1999 Version 8.02; SAS Institute Inc, Cary: PROC CALIS). The variables are assumed to have an approximately multivariate normal distribution for the maximumlikelihood estimation procedure. The option NOINT was used to specify that no intercept be used in the linear equations as required with the use of phylogenetic independent contrasts [40]. The coefficients were parameterized using iterative normal-theory maximum likelihood.

Model appropriateness was indicated by the following model information. The optimization parameters include the goodness-of-fit statistics, which indicate the appropriateness of the linear structural equation model for the given data set (covariance matrix). Chi-square measure is the likelihood ratio test statistic for the null hypothesis that the predicted matrix has specified model structure against the alternative that the matrix is unconstrained. The probability denotes the likelihood under the null hypothesis of obtaining a greater 
Chi-square statistic and here, a larger $p$ indicates better model fit. The Bayesian information criteria (BIC or Schwarz's information criterion; [47]) is similar to AIC and helps to determine the best number of parameters with the smallest value being considered more appropriate. For small sample sizes and with maximum-likelihood estimation, AIC is the preferred measure of model appropriateness [48]. Thus, statistically the model that yields the smallest value of $\mathrm{BIC}$ or AIC was considered best.

All 40 models (20 for body size and 20 for dimorphism) were tested for absolute fit as well as relative fit by comparing models based on goodness-of-fit statistics [27]. Model comparisons were done using the Kullback-Leibler information approach with modified Akaike's Information Criterion for small samples [27]. $\mathrm{AIC}_{\mathrm{c}}$ was calculated as

$\mathrm{AIC}_{\mathrm{c}}=-2 \ln L(\theta)-2 K+2 K(K+1) /(n-K-1)$

where $\ln L(\Theta)$ is the value of the maximized log-likelihood over the unknown parameters $(\Theta)$ given the data and the model, $K$ is the number of parameters, and $n$ is the sample size. Akaike differences $\left(\Delta_{\mathrm{i}}\right)$ and normalized Akaike weights were calculated $\left(w_{\mathrm{i}}\right)$. In general, where $\Delta_{\mathrm{i}}<2.0$, the models were considered to have substantial support [49].

\section{RESULTS}

Many of the independent contrast traits were correlated, particularly among the five environmental variables (Table 1). Some relevant relationships included: male mass better related to sexual size dimorphism than female mass; density decreased and home range increased with body mass; and greater sexual size dimorphism was associated with greater snow on ground.

\section{Body Size Models}

We tested for the directional cause and effect of environment, behaviour, and body size relationships among 20 separate models. Seven models were supported statistically based on the Kullback-Leibler information approach (Table 2). For the body size model, the best cause and effect grouping of explanatory variables $\left(\Delta_{\mathrm{i}}<1.0\right)$ indicated relationships between primary productivity or seasonality, home range size or density, and body size (Fig. 2A). Snow and latitude were adequate explanatory variables only with reduced model acceptance $1.0<\Delta_{\mathrm{i}}<2.0$ and having range or density as intermediate variables. For none of the seven acceptable pathways, did density significantly affect home range or home range affect density (i.e., only one intermediate variable was supported). In other words, either environment acted on home range and then body size or environment acted on density and then body size never did environment act on home range which acted on density which acted on body size.

In the case of density, seasonality was negatively related to density and density was negatively related to body size. Thus, higher latitude and greater seasonality related to lower population density, which favored the evolution of larger

Table 1. Correlation Matrix of Independent Contrasts for Nine Traits from 101 Carnivore Species. Pearson's Correlation Coefficient, Probability, Sample Size

\begin{tabular}{|c|c|c|c|c|c|c|c|c|c|}
\hline Trait & $\begin{array}{c}\text { Female } \\
\text { Mass }\end{array}$ & $\begin{array}{l}\text { Male } \\
\text { Mass }\end{array}$ & Dimorphism & Latitude & $\begin{array}{c}\text { Primary Pro- } \\
\text { ductivity }\end{array}$ & Temperature & Snow & Seasonality & Density \\
\hline Male mass & $\begin{array}{r}+0.933 \\
0.0001 \\
101\end{array}$ & & & & & & & & \\
\hline Dimorphism & $\begin{array}{r}-0.045 \\
0.63 \\
101\end{array}$ & $\begin{array}{r}0.266 \\
0.003 \\
101\end{array}$ & & & & & & & \\
\hline Latitude & $\begin{array}{r}+0.129 \\
0.16 \\
101\end{array}$ & $\begin{array}{r}+0.150 \\
0.10 \\
101\end{array}$ & $\begin{array}{r}+0.089 \\
0.33 \\
101\end{array}$ & & & & & & \\
\hline Primary Productivity & $\begin{array}{r}-0.028 \\
0.76 \\
101\end{array}$ & $\begin{array}{r}-0.018 \\
0.85 \\
101\end{array}$ & $\begin{array}{r}+0.018 \\
0.84 \\
101\end{array}$ & $\begin{array}{r}-0.749 \\
0.0001 \\
101\end{array}$ & & & & & \\
\hline Seasonality & $\begin{array}{r}+0.065 \\
0.48 \\
101\end{array}$ & $\begin{array}{r}+0.087 \\
0.34 \\
101\end{array}$ & $\begin{array}{r}+0.139 \\
0.13 \\
101\end{array}$ & $\begin{array}{r}+0.792 \\
0.0001 \\
101\end{array}$ & $\begin{array}{r}-0.782 \\
0.0001 \\
101\end{array}$ & $\begin{array}{r}-0.535 \\
0.0001 \\
101\end{array}$ & $\begin{array}{r}+0.521 \\
0.0001 \\
101\end{array}$ & & \\
\hline Density & $\begin{array}{r}-0.476 \\
0.0001 \\
59\end{array}$ & $\begin{array}{r}-0.490 \\
0.0001 \\
59\end{array}$ & $\begin{array}{r}-0.027 \\
0.84 \\
59\end{array}$ & $\begin{array}{r}-0.096 \\
0.47 \\
59\end{array}$ & $\begin{array}{r}+0.055 \\
0.68 \\
59\end{array}$ & $\begin{array}{r}+0.128 \\
0.33 \\
59\end{array}$ & $\begin{array}{r}-0.087 \\
0.51 \\
59\end{array}$ & $\begin{array}{r}-0.146 \\
0.27 \\
59\end{array}$ & \\
\hline Home Range & $\begin{array}{r}+0.502 \\
0.0001 \\
70\end{array}$ & $\begin{array}{r}+0.535 \\
0.0001 \\
70\end{array}$ & $\begin{array}{r}+0.137 \\
0.26 \\
70\end{array}$ & $\begin{array}{r}+0.137 \\
0.26 \\
70\end{array}$ & $\begin{array}{r}-0.134 \\
0.27 \\
70\end{array}$ & $\begin{array}{r}-0.245 \\
0.04 \\
70\end{array}$ & $\begin{array}{r}+0.129 \\
0.29 \\
70\end{array}$ & $\begin{array}{r}+0.191 \\
0.11 \\
70\end{array}$ & $\begin{array}{r}-0.376 \\
0.008 \\
49\end{array}$ \\
\hline
\end{tabular}


Table 2. Results from a Comparison of 40 Structural Equation Models Derived Using Data for 101 Species of Mammalian Carnivores

\begin{tabular}{|l|c|c|c|c|c|c|c|c|c|}
\hline \multicolumn{1}{|c|}{ Model Rank (Best to Worst) } & $\boldsymbol{R}^{2}$ & Chi-Square & $p$ & BIC $^{\prime}$ & AIC $_{\mathbf{c}}$ & $\Delta_{\mathbf{i}} \mathbf{A I C}_{\mathbf{c}}$ & $\mathbf{w}_{\mathbf{i}}$ \\
\hline \hline (A) Female Body Size Models: & 0.252 & 0.04 & 0.83 & -4.20 & -1.61 & 0.00 & 0.1475 \\
\hline$p p \rightarrow$ range $\rightarrow$ size & 0.253 & 0.06 & 0.80 & -4.19 & -1.59 & 0.02 & 0.1462 \\
\hline season $\rightarrow$ range $\rightarrow$ size & 0.228 & 0.16 & 0.69 & -3.92 & -1.49 & 0.12 & 0.1391 \\
\hline$p p \rightarrow$ density $\rightarrow$ size & 0.238 & 0.88 & 0.35 & -3.20 & -0.78 & 0.83 & 0.0974 \\
\hline season $\rightarrow$ density $\rightarrow$ size & 0.268 & 1.44 & 0.23 & -2.81 & -0.212 & 1.40 & 0.0733 \\
\hline snow $\rightarrow$ range $\rightarrow$ size & 0.270 & 1.68 & 0.195 & -2.56 & 0.028 & 1.64 & 0.0650 \\
\hline latitude $\rightarrow$ range $\rightarrow$ size & 0.251 & 1.85 & 0.174 & -2.23 & 0.196 & 1.81 & 0.0598 \\
\hline latitude $\rightarrow$ density $\rightarrow$ size & &
\end{tabular}

(B) Sexual Size Dimorphism Models:

\begin{tabular}{|c|c|c|c|c|c|c|c|}
\hline$p p \rightarrow$ range $\rightarrow$ density $\rightarrow$ dim & 0.100 & 3.93 & 0.269 & -7.74 & -1.55 & 0.00 & 0.253 \\
\hline season $\rightarrow$ density $\rightarrow$ dimorphism & 0.071 & 0.71 & 0.100 & -3.37 & -0.95 & 0.60 & 0.187 \\
\hline lat $\rightarrow$ range $\rightarrow$ density $\rightarrow$ dimorphism & 0.106 & 4.69 & 0.200 & -6.98 & -0.78 & 0.77 & 0.172 \\
\hline snow $\rightarrow$ density $\rightarrow$ dimorphism & 0.023 & 1.32 & 0.251 & -2.76 & -0.34 & 1.21 & 0.138 \\
\hline
\end{tabular}

Only the models with substantial support are presented (see methods). (A) The two environment variables, seasonality (season) and primary productivity (pp) influenced body size via home range size and population density. (B) Environmental variables influences sexual size dimorphism (dim $=$ male/female body mass) via home range size (range) and population density. Variables are standardized contrasts that control for phylogenetic effects.

Statistics used to assess model appropriateness: $R^{2}$ estimates model explanatory power and were derived using general linear models. Chi-square measure is the optimum function value $F$ multiplied by $(N-1)$. A greater Chi-square statistic with a higher $p$ value indicates a more reliable model. BIC $=$ Bayesian information criteria (Schwarz's Information Criterion) $=-2 \log (£)+\mathrm{K} * \log (n)$. AIC $=$ second order Akaike information criteria (AIC $\left.=n \log \left(\sigma^{2}\right)+2 K\right)$ is a general criterion for choosing the best number of parameters to include in a model. $\mathrm{AIC}_{\mathrm{c}}=$ bias adjusted $\mathrm{AIC}$ for small sample size $=\mathrm{AIC}+\left(2 K(K+1) /(n-K-1)\right.$ where $K$ is the total number of estimated regression parameters including $\sigma^{2}$ (no intercept) and $n$ is sample size. $\Delta_{\mathrm{i}}=\mathrm{AIC}$ differences computed as $\mathrm{AIC}_{\mathrm{i}}-\mathrm{AIC}_{\min } \cdot \mathrm{w}_{\mathrm{i}}=\exp \left(-1 / 2 \Delta_{\mathrm{i}}\right) / \sum \exp \left(-1 / 2 \Delta_{\mathrm{r}}\right)$.

body size. The explained variation $\left(R^{2}\right)$ was consistent among body size models with approximately $25 \%$ of the variation explained $(0.23-0.27)$.

In the case of home range, primary productivity was positively related to home range size while seasonality was negatively related, and home range size was positively related to body size. Thus, greater snow, at high latitudes, with low primary productivity, and high seasonality related to individuals occupying larger home ranges and this favored the evolution of larger body size. We tested for all pathways that started with environment as the cause and in no instance did temperature provide a significant model (results not shown).

\section{Sexual Dimorphism Models}

Of the 20 sexual dimorphism models tested, the three best causal grouping of variables $\left(\Delta_{\mathrm{i}}<1.0\right)$ indicated that the environment acted directly on density or indirectly through home range, which then influenced dimorphism (Fig. 2B). Here, greater seasonality related to lower population density which related to greater sexual size dimorphism. Alternatively, living at high latitudes with low primary productivity related to individuals occupying large home ranges, which related to reduced population density and greater dimorphism.

Two models were supported with lower acceptance criteria $\left(1.0<\Delta_{\mathrm{i}}<2.0\right)$. One model indicated that snow on the ground directly influenced dimorphism with greater snowfall being correlated with greater dimorphism. In the other model, greater latitude was associated with greater range size which in turn correlated with lower population density and then finally low density was associated with greater sexual size dimorphism. This latter model was the only complex (4 variable) model supported of the 40 models tested. In none of the pathways did temperature provide a statistically adequate explanation of the evolution of sexual size dimorphism. The explained variation $\left(R^{2}\right)$ was approximately $10 \%$ $(0.03-0.11)$ among size dimorphism models.

\section{DISCUSSION}

Here, we have formulated a novel hypothesis and provided evidence that environment may affect body size through the intermediate, social behaviour. Current evidence already suggests that Carnivora follow Bergmann's rule with greater body size associated with high latitudes $[43,50]$ and that evolution of body size and sexual size dimorphism in mammals is likely a result of multiple factors [46, 51]. Larger body size at northern latitudes (i.e., Bergmann's rule) was originally explained in terms of advantages for heat conservation [52]; but see [53]. However, non-physiological benefits of larger body size may include greater mobility and ability to range more widely to overcome local fluctuations in abundance of food and mates. For example, reproductive strategies may ultimately be derived from living in highlatitude environments but the proximate selection pressure is social behaviour and mating systems $[14,18,54]$. Indirectly we test whether body size and dimorphism evolve together and found that both responded to the same environmental pressures. Thus, these relationships support that both are under similar environmental selection pressure and may be responding to similar relationships [23]. 
(A)

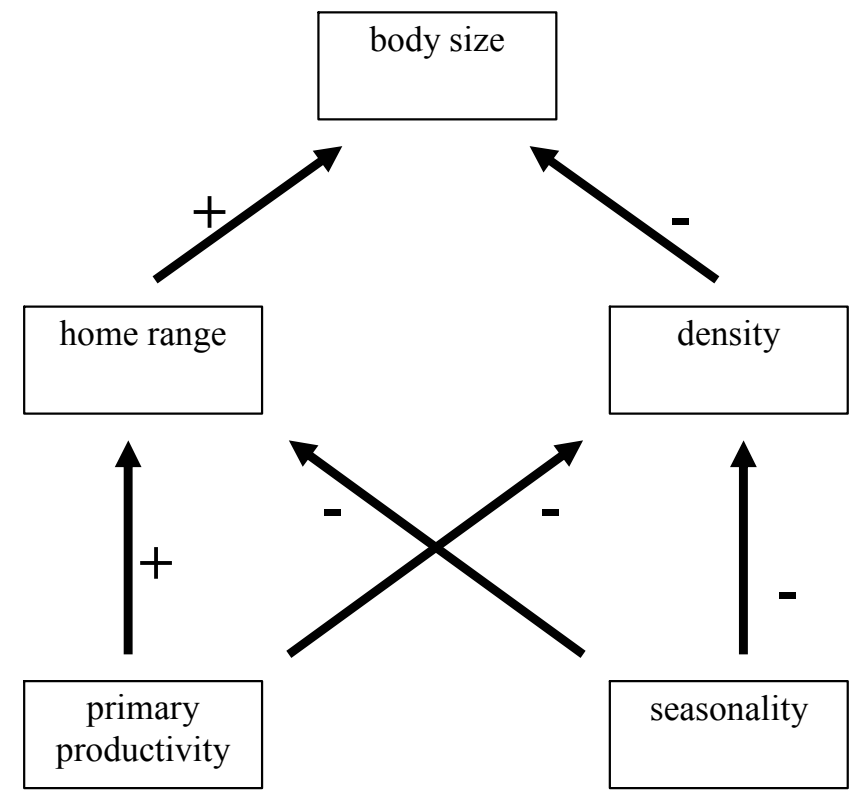

(B)

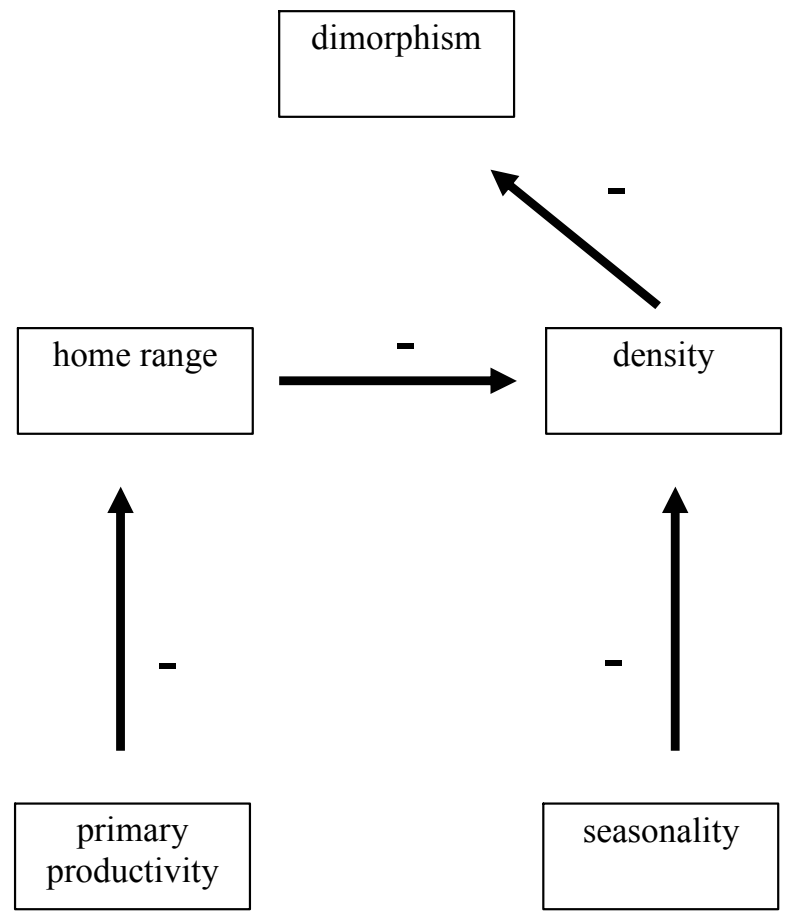

Fig. (2). Two structural equation models representing the relationships among explanatory variables influencing (A) body size and (B) sexual size dimorphism for 101 species of mammalian carnivores. Relationships shown were derived from models with $\Delta_{\mathrm{i}}<1.0$ (Table 2). Arrows depict the proposed links between variables. Positive (+) and negative (-) parameterized regression coefficients are associated with each link (see Table $\mathbf{2}$ error terms $=1-R^{2}$ ).

Our results suggest that a potential link between environmental selection pressures and body size both among (species) and within (intrasexual) is spacing behaviour. The evolution of larger body size with high-latitude environments provides for greater mobility as a means of overcoming spatio-temporal fluctuations in food and mate availability. For terrestrial mammals, greater mobility is beneficial to overcome seasonal fluctuations in food availability and larger body size may ameliorate the costs associated with travel through the season of snow and ice. In high latitude environments, accumulation of snow during winter increases relative locomotory costs $[55,56]$, and may reduce movement distances or exact an energetic cost. Similarly, areas of greater seasonality, e.g., fluctuations in ice, are associated with large home ranges [57, 58]. Not surprising, home range scales with body mass for a wide range of taxonomic groups, including carnivores $[4,57,59-62]$. The link between body size and mobility is evidenced by the positive correlation between body sizes and both home range size and dispersal distance [63]. Thus, greater body size may have evolved in high latitude environments to reduce locomotory costs and allow travel over large distances in areas of dispersed and/or reduced food availability, particularly during winter and with snow cover.

A latitudinal gradient results in greater temporal fluctuations at high latitudes [64] and increased randomness [65, 66]. Similarly, seasonality has been shown to influence sexual size dimorphism through its effect on the distribution and abundance of resources, both food and mates $[10,67]$. In the current analysis, terrestrial mammalian carnivores were characterized by (1) greater relative body size with greater mobility (larger home ranges) and lower population density; (2) higher latitude and greater seasonality reduced population density, which increased body size; (3) higher latitude and lower primary productivity increased home range size, which favoured larger body size; and (4) body size was not influenced by temperature either directly or through spacing behaviour.

Additionally, increased mobility associated with larger size may facilitate mate searching, influence mate choice, and ultimately select for different mating systems. Here, the evolution of larger body size was related to the increased likelihood of greater sexual dimorphism in size, a relationship referred to as "Rensch's rule" [67-70] but see [71] and was best associated with primary productivity and seasonality $[15,72]$. Most carnivores (95 of 109; 8 females larger and 6 monomorphic) are male-biased sexually dimorphic (males larger than females [28]. Structural equation modelling indicated that (1) changes in sexual size dimorphism occurred via the intermediates of home range or density but not both, (2) density decreased with seasonality causing greater dimorphism, (3) greater latitude and lower primary productivity resulted in greater home range, which resulted in lower population density, which resulted in greater dimorphism, and (4) temperature did not affect spacing or dimorphism. Sexual dimorphism among mammalian carnivores has been related to mating systems [28] with polygynous species associated with greater latitude $\left(45^{\circ}\right)$ relative to monogamous $\left(34^{\circ}\right)$ or multi-male mating species $\left(29^{\circ}\right)$. Polygynous species had a mean male/female body mass ratio of 4.01 ; species with monogamous mating system had a mean ratio of 1.15; and multi-male species a mean of 1.33 .

One mechanistic explanation for why home range size links seasonality with body size is that the allometric relationship of home range size (1.0) [73] and density (0.75) [74, 75] increase at different rates (body mass exponents) resulting in greater overlap of individuals within populations for larger bodied species [76]. Hence, the evolution of large bod- 
ied males with latitude may be for the selective advantages afforded by greater mobility and increased opportunities for mating $[20,77]$. For most species, mating and spacing systems covary with ecological conditions [78], especially with local density. For example, male mating system depends on female dispersion, which itself depends on resource dispersion and predation [79-81]. The effects of environmental selection pressure and evolution of sociality leading to sexual dimorphism has been postulated for ungulates [51, 82]. For example, high population density affects food availability and subsequently growth rates which likely affect males and females differentially [67]. Similarly, population density will affect the contact between individuals influencing mating synchrony which can affect polygyny and degree of sexual size dimorphism [46]. However, population adjustments connecting environment and body size are proximate mechanisms that occur at the individual-population level, whereas our current analysis refers to ultimate explanations (evolutionary why questions) that emerge at the species level.

Natural selection acts to adapt life histories to particular environmental selection pressures. However, environment may act on certain life history parameters that then cause a mosaic shift in a suite of parameters. We substantiated previous research that illustrates the importance of energy (primary productivity) and variation in the distribution of energy (e.g., seasonality as temporal distribution) as predominant environmental characteristics influencing evolution ([83-86]. Knowledge of life-history evolution has progressed to the stage whereby evolutionary ecology can ask how these multiple interactions occur. Environmental seasonality has been proposed as an important selection pressure on animals occupying northern environments [4, 87-89]. Here, carnivores in more seasonal high latitude environments have tended to evolve to greater body size and to greater sexual size dimorphism. Selection pressures associated with the unpredictability of high-latitude environments may have (1) favoured terrestrial mammalian carnivores occupying larger home ranges and living at lower density relative to animals living in less variable environments and (2) species living at low densities and having to roam over large areas evolved greater relative body size and/or male size to counter the difficulty of finding food and mates, respectively. Presumably, large body size facilitates greater movement distances and ease of locomotion in winter through snow in terrestrial environments and selection for greater body mass in these environments is stronger for males.

\section{ACKNOWLEDGEMENTS}

NSERC Discovery Grants provided funding for both authors. Three anonymous reviewers provided valuable assistance.

\section{REFERENCES}

[1] Rosenzweig ML. Net primary productivity of terrestrial communities: prediction from climatological data. Am Nat 1968; 102: 67-74.

[2] Geist V. Bergmann's rule is invalid. Can J Zool 1987; 65: 1035-8.

[3] Calder WA III. Ecological scaling: mammals and birds. Ann Rev Ecol Sys 1983; 14: 213-30.

[4] Lindstedt SL, Boyce MS. Seasonality, fasting endurance, and body size in mammals. Am Nat 1985; $125: 873-8$.

[5] Dunbrack RL, Ramsay MA. The allometry of mammalian adaptations to seasonal environments: a critique of the fasting endurance hypothesis. Oikos 1993; 66: 336-342.
[6] Ashton KG, Tracy MC, de Queiroz A. Is Bergmann's rule valid for mammals? Am Nat 2000; 156: 390-415.

[7] Angilletta MJ Jr, Nieiarowski PH, Dunham AE, Leachè AD, Porter WP. Bergmann's clines in ectotherms: illustrating a life-history perspective with Sceloporine lizards. Am Nat 2004; 164: E168E183.

[8] Bergmann C. Ueber di Verhaeltnisse der Waermeoekonomie der Thiere zu ihrer Groesse. Goettinger Studien 1847; 1: 595-708.

[9] McNab BK. On the comparative ecological and evolutionary significance of total and mass-specific rates of metabolism. Physiol Biochem Zool 1999; 72: 642-4.

[10] Isaac JL, Johnson CN. Sexual dimorphism and synchrony of breeding: variation in polygyny potential among populations in the common brushtail possum, Trichosurus vulpecula. Behav Ecol 2003; 14: 818-22.

[11] Graves GR. Bergmann's rule near the equator: latitudinal clines in body size of an Andean passerine bird. Proc Natl Acad Sci USA 1991; 88: 2322-5.

[12] Currie DJ. Energy and large-scale patterns of animal species and plant species richness. Am Nat 1991; 137: 27-49.

[13] Badyaev AV. Altitudinal variation in sexual dimorphism: a new pattern and alternative hypotheses. Behav Ecol 1997; 8: 675-90.

[14] Ferguson SH, Higdon JW, Larivière S. Does seasonality explain the evolution and maintenance of delayed implantation in the family Mustelidae (Mammalia: Carnivora)? Oikos 2006; 114: 249-56.

[15] Quin DG, Smith AP, Norton TW. Eco-geographic variation in size and sexual dimorphism in sugar gliders (Marsupialia: Petauridae). Aust J Zool 1996; 44: 19-45.

[16] Partridge L, Barrie B, Fowler K, French V. Evolution and development of body size and cell size in Drosophila melanogaster in response to temperature. Evolution 1994; 48: 1269-76.

[17] Fischer AG. Latitudinal variations in organic diversity. Evolution 1960; 14: 64-81.

[18] Bennet PM, Owens IPF. Evolutionary ecology of birds: life histories, mating systems, and extinction. Oxford: Univ Press; 2002.

[19] Badyaev AV, Hill GE. Avian sexual dichromatism in relation to phylogeny and ecology. Ann Rev Ecol Evol Syst 2003; 34: 27-49.

[20] Andersson M. Sexual selection. Princeton: Univ Press; 1994.

[21] Sims K. In: Brooks R, Maes P, Eds. Artificial Live IV; MIT Press 1994; 28-39.

[22] Arnqvist G, Danielsson I. Copulatory behaviour, genital morphology, and male fertilization success in water striders. Evolution 1999; 53: 147-56.

[23] Blanckenhorn WU, Stillwell RC, Young KA, Fox CW, Ashton KG. When Rensch meets Bergmann: does sexual size dimorphism change systematically with latitude? Evolution 2006; 60: 2004-11.

[24] Harvey PH, Pagel MD. The comparative method in evolutionary biology. Oxford: Univ Press; 1991.

[25] Garland T Jr, Dickerman AW, Janis CM, Jones JA. Phylogenetic analysis of covariance by computer simulation. Syst Biol 1993; 42: 265-92.

[26] Shipley B. Cause and correlation in biology: a user's guide to path analysis, structural equations and causal inference. Cambridge: Cambridge Univ Press; 2000.

[27] Burnham KP, Anderson DR. Model selection and multimodel inference: a practical information-theoretic approach. Springer; 2002.

[28] Ferguson SH, Larivière S. Are long penis bones an adaptation to high latitude snowy environments? Oikos 2004; 105: 255-67.

[29] Cox RM, Skelly SL, John-Alder HB. A comparative test of adaptive hypotheses for sexual size dimorphism in lizards. Evolution 2003: 57: 1653-69.

[30] Gaston KJ, Blackburn TM. Global Scale Macroecology: Interactions between Population Size, Geographic Range Size and Body Size in the Anseriformes. J Anim Ecol 1996; 65: 701-14.

[31] Bininda-Emonds ORP, Gittleman JL, Purvis A. Building large trees by combining phylogenetic information: a complete phylogeny of the extant Carnivora (Mammalia). Biol Rev 1999; 74: 143-75.

[32] Wozencraft WC. In: Wilson DE, Reeder DM, Eds. Mammal species of the world: a taxonomic and geographic reference. Smithsonian Press 1993; 279-348.

[33] Willmott CJ, Rowe CM, Mintz Y. Climatology of the terrestrial seasonal water cycle. J Climat 1985; 5: 589-606.

[34] Thornthwaite CW. An approach toward a rational classification of climate. Geogr Rev 1948; 38: 55-69. 
[35] Ferguson SH, Larivière S. Can comparing life histories help conserve carnivores? An Cons 2002; 5: 1-12.

[36] Ferguson SH, McLoughlin PD. Effect of energy availability, seasonality, and geographic range on brown bear life history. Ecography 2000; 23: 193-200.

[37] Kaspari M, O'Donnell S, Kercher JR. Energy, density, and constraints to species richness: ant assemblages along a productivity gradient. Am Nat 2000; 155: 280-93.

[38] Leith H. In: Leith H, Whittaker RH, Eds. Modelling the primary productivity of the world. Berlin; Springer 1976; 237-263.

[39] Felsenstein J. Phylogenies and the comparative method. Am Nat 1985; 125: 1-15.

[40] Garland T Jr, Midford PE, Jones JA, Dickerman AW, Diaz-Uriarte R. PDAP: Phenotypic Diversity Analysis Programs, Version 6.0. University of California; 2001.

[41] Purvis A, Rambaut A. Comparative analysis by independent contrasts (CAIC): an Apple Macintosh application for analyzing comparative data. Comp Appl Biosc 1995; 11: 247-51.

[42] Lawton JH. Patterns in ecology. Oikos 1996; 75: 145-7.

[43] Meiri S, Dayan T. On the validity of Bergmann's rule. J Biogeog 2003; 30: 331-51.

[44] Anderson DR, Burnham KP, Thompson WL. Null hypothesis testing: problems, prevalence, and an alternative. J Wildl Manage 2000; 64: 912-23.

[45] McIntire EJB. Understanding natural disturbance boundary formation using spatial data and path analysis. Ecology 2004; 85: 193343.

[46] Isaac JL. Potential causes and life-history consequences of sexual size dimorphism in mammals. Mammal Rev 2006; 35: 101-15.

[47] Schwarz G. Estimating the Dimension of a Model. Ann Stat 1978; 6: 461-4.

[48] Bozdogan H. Model selection and Akaike's Information Criterion (AIC): The general theory and its analytical extensions. Psychometrika 1987; 52: 345-70.

[49] Vucetich JA, Peterson RO. The influence of prey consumption and demographic stochasticity on population growth rate of Isle Royale wolves Canis lupus. Oikos 2004; 107: 309-20.

[50] Meiri S, Dayan T, Simberlogg D. Carnivores, biases and Bergmann's rule. Biol J Linn Soc 2004; 81: 579-88.

[51] Loison A, Gaillard J-M, Pélabon C, Yoccoz NG. What factors shape sexual size dimorphism in ungulates? Evol Ecol Res 1999; 1: 611-33.

[52] Mayr E. Geographic character gradients and climatic adaptation. Evolution 1956; 10: 105-8.

[53] Queiroz deA, Ashton KG. The phylogeny of a species-level tendency: species heritability and possible deep origins of Bergmann's Rule in tetrapods. Evol 2004; 58: 1674-84.

[54] Costa DP. Reproductive and foraging energetics of high latitude penguins, albatrosses and pinnipeds: implications for life history patterns. Am Zool 1991; 31: 111-30.

[55] Parker KL, Robbins CT, Hanley TA. Energy expenditures for locomotion by mule deer and elk. J Wildl Manage 1984; 48: 474-88.

[56] Crête M, Larivière S. Estimating the costs of locomotion in snow for coyotes. Can J Zool 2003; 81: 1808-14.

[57] McNab BK. Bioenergetics and the determination of home range size. Am Nat 1963; 97: 133-40.

[58] Ferguson SH, Taylor MK, Born EW, Rosing-Asvid A, Messier F. Determinants of range size in polar bears (Ursus maritimus). Ecol Lett 1999; 5: 311-8.

[59] Harestad AS, Bunnell FL. Home range and body weight a reevaluation. Ecology 1979; 60: 389-402.

[60] Gompper ME, Gittleman JL. Home range scaling: interspecific and comparative trends. Oecologia 1991; 87: 343-8.

[61] McLoughlin PD, Ferguson SH. A hierarchical pattern of limiting factors helps explain variation in home range size. Écoscience 2000; 7: 123-30.

[62] Mysterud A, Péreq-Barberia FJ, Gordon IJ. The effect of season, sex and feeding style on home range area versus body mass scaling in temperate ruminants. Oecologia 2001; 127:30-9.
[63] Bowman J, Jaeger JAG, Fahrig L. Dispersal distance of mammals is proportional to home range size. Ecology 2002; 83: 2049-55.

[64] Pawar SS. Geographical variation in the rate of evolution: effect of available energy or fluctuating environment? Evolution 2005; 59: 234-37.

[65] Ferguson SH, Messier F. Ecological implications of a latitudinal gradient in inter-annual climatic variability: a test using fractal and chaos theories. Ecography 1996; 19: 382-92.

[66] Vasseur DA, Yodzis P. The color of environmental noise. Ecology 2004; 85: 1146-52.

[67] Weckerly FW. Sexual-size dimorphism: influence of mass and mating systems in the most dimorphic mammals. J Mamm 1998; 79: 33-52.

[68] Rensch B. Some problems of geographical variation and species formation. Proc Linn Soc Lond 1938; 150: 275-85.

[69] Abouheif E, Fairbairn D. Comparative analysis of allometry for sexual size dimorphism: assessing Rensch's rule. Am Nat 1997; 149: 540-62.

[70] Colwell RK. Rensch's rule crosses the line: convergent allometry of sexual size dimorphism in hummingbirds and flower mites. Am Nat 2000; 156: 495-510

[71] Lindenfors P, Tullberg BS, Biuw M. Phylogenetic analyses of sexual selection and sexual size dimorphism in pinnipeds. Behav Ecol Sociobiol 2002; 52: 188-93.

[72] Schauble CS. Variation in body size and sexual dimorphism across geographical and environmental space in the frogs Limnodynastes tasmaniensis and L. peronii. Biol J Linnean Soc 2004; 82: 39-56.

[73] Lindstedt SL, Miller BJ, Buskirk SW. Home range, time and body size in mammals. Ecology 1986; 67: 413-8.

[74] Owen-Smith N. Megaherbivores: the influence of very large body size on ecology. Cambridge Univ Press; 1988.

[75] Damuth J. Home range, home range overlap and species energy use among herbivorous mammals. Biol J Linn Soc 1981; 75: 185-93.

[76] Calder WA III. Size, function and life history. Harvard Univ Press; 1984.

[77] Lindenfors P. Sexually antagonistic selection on primate size. J Evol Biol 2002; 15: 595-607.

[78] Lott DF. Intraspecific variation in the social systems of wild vertebrates. Cambridge Univ Press; 1991.

[79] LaBarbera M. Analyzing body size as a factor in ecology and evolution. Annu Rev Ecol Syst 1989; 20: 97-117.

[80] Kruuk HH. Wild otters: predation and populations. Oxford Univ Press; 1995.

[81] Ferguson SH. The Influences of environment, mating habitat, and predation on evolution of pinniped lactation strategies. J Mammal Evol 2006; 13: 63-82

[82] Pérez-Barbería FJ, Gordon IJ, Pagel M. The origins of sexual dimorphism in body size in ungulates. Evolution 2002; 56: 1276-85.

[83] Quinn JF, Dunham AE. On hypothesis testing in ecology and evolution. Am Nat 1983; 122: 602-17.

[84] Ferguson SH. The effects of productivity and seasonality on life history: comparing age at maturity among moose (Alces alces) populations. Glob Ecol Biogeog 2002; 11: 303-12.

[85] Ferguson SH, Higdon JW. How seals divide up the world: environment, life-history, and conservation. Oecologia 2006; 150: 31829.

[86] Ferguson SH, Larivière S. In: Harrison DJ, Fuller AK, Proulx G. Eds. Is mustelid life history different? Norwell, MS, Kluwer Acad Publ 2004; 2-19.

[87] Ferguson SH, Virgl JA, Larivière S. Evolution of delayed implantation and associated grade shifts in life history traits of North American carnivores. Ėcoscience 1996; 3: 7-17.

[88] Larivière S, Ferguson SH. Evolution of induced ovulation in North American carnivores. J Mamm 2003; 84: 937-47.

[89] Slabbekoorn H, Smith TB. Habitat-dependent song divergence in the little greenbul: an analysis of environmental selection pressures on acoustic signals. Evolution 2002; 56: 1849-58. 